\title{
Twelve Months Clinical Outcomes after Percutaneous Coronary Intervention with Bare Metal Stents in Unselected Real-Life Patients with Coronary Artery Disease: Results from FLEXUS Study
}

\author{
Durgaprasad Rajasekhar*, Velam Vanajakshamma, Gajjala Obul Reddy, Akkulagari Vamsidhar, \\ Kasala Latheef, Pathakota Sudhakar Reddy
}

Department of Cardiology, Sri Venkateswara Institute of Medical Sciences (SVIMS), Tirupati, India

Email: *drdrsekhar@gmail.com

How to cite this paper: Rajasekhar, D., Vanajakshamma, V., Reddy, G.O., Vamsidhar, A., Latheef, K. and Reddy, P.S. (2016) Twelve Months Clinical Outcomes after Percutaneous Coronary Intervention with Bare Metal Stents in Unselected Real-Life Patients with Coronary Artery Disease: Results from FLEXUS Study. World Journai of Cardiovascular Diseases, 6, 342-351. http://dx.doi.org/10.4236/wjcd.2016.610040

Received: August 29, 2016

Accepted: October 7, 2016

Published: October 10, 2016

Copyright (c) 2016 by authors and Scientific Research Publishing Inc. This work is licensed under the Creative Commons Attribution International License (CC BY 4.0).

http://creativecommons.org/licenses/by/4.0/ (c) (i) Open Access

\begin{abstract}
Background: Though drug-eluting stent is widely used during coronary angioplasty, still there are conditions in which bare metal stents possess a priority role. Objectives: The aim of FLEXUS study is to investigate the safety and efficacy of Flexinnium stent in unselected real-life patients. Methods: The FLEXUS is a single-centric, observational, non-randomized, retrospective study performed from January to August 2014 in 216 patients who received Flexinnium stent. The end-point of study included device-oriented and patient-oriented clinical outcomes as per Academic Research Consortium consensus. These end-points were observed at in-hospital stay and 12-month follow-up. Results: Of 216 patients, 174 (80.6\%) patients were male; there were $76(35.2 \%)$ and $84(38.9 \%)$ patients of diabetes and hypertension, respectively. Type B2 and C lesions accounted for 27 (11.3\%) and 122 (50.8\%), respectively. A total of 241 Flexinnium stents were implanted with an average diameter and length of $2.7 \pm 0.2 \mathrm{~mm}$ and $21.6 \pm 8.0 \mathrm{~mm}$, respectively. The cumulative device-oriented composite at 12 -month follow-up included $2.31 \%$ cardiac death, $1.39 \%$ myocardial infarction (MI) attributed to the target vessel, and 3.70\% target lesion revascularization (TLR). Conclusion: FLEXUS study gives an idea about favorable safety and efficacy of the Flexinnium in unselected real-life patients with both simple and complex coronary lesions.
\end{abstract}

\section{Keywords}

Bare Metal Stent, Coronary Artery Disease, Percutaneous Coronary Intervention 


\section{Introduction}

Percutaneous coronary intervention (PCI) with stenting has escalated as the most common method of myocardial revascularization [1]. The use of coronary stents has surged primarily due to increased efficacy of stents as compared to balloon angioplasty. The coronary stents provide better short- and long-term outcomes as well as improved safety and efficacy of PCI by reducing abrupt or threatened vessel closure and curtailing restenosis when weighed against balloon angioplasty [2] [3]. Although drug-eluting stents are widely used for the treatment of patients with coronary artery disease, baremetal stents (BMS) are still useful in some situations, especially in patients with contraindication to prolonged antiplatelet therapy [4].

The Flexinnium (Sahajanand Medical Technologies Pvt. Ltd., Surat, India) coronary stent system includes L605 Cobalt Chromium alloy (Co-Cr alloy) stent located on balloon catheter between two radiopaque markers. The Flexinnium Co-Cr coronary stent is intended to improve coronary luminal diameters as an adjunct to coronary interventions. These being bare metal stents are intended as permanently implanted devices. They are characterized by their excellent corrosion resistance, high ductility, and high modulus of elasticity. The corrosion resistance of $\mathrm{Co}-\mathrm{Cr}$ alloy is better than stainless steel. Because of the carbide in Co-Cr alloy structure, it has excellent wear resistance in comparison to stainless steel. Thus, the aim of FLEXUS study is to investigate the safety and efficacy of Flexinnium stent in unselected real-life patients undergoing coronary angioplasty.

\section{Methods}

\subsection{Study Design and Patient Population}

The FLEXUS is a single-centric, observational, non-randomized, retrospective study conducted to validate the performance of Flexinnium coronary stent system in the real-life unselected patients. Between January and August 2014, 216 consecutive patients, who received Flexinnium stent, were enrolled in the study. The study was conducted in accordance with the Declaration of Helsinki and country-specific regulatory requirements. All patients signed informed consent form which was reviewed and approved by the Institutional ethical committee of the centre.

The inclusion criteria for the study were: patients of age 18 years or above; patients who had stable or unstable angina or acute recent myocardial infarction; patients who were undergoing coronary intervention with the study stent during January to August 2014. The patients were excluded if they refused to give written informed consent or if they had any known allergy to aspirin, clopidogrel, ticlopidine, heparin and cobalt chromium.

\subsection{Description of the Study Stent}

The Flexinnium coronary stent system consists of L605 Co-Cr alloy located on balloon catheter between two radiopaque markers. Cobalt-chromium alloy has high tensile properties making possible thinner struts without decreasing radial strength. The alloy 
has been chosen for its biocompatibility, radiopacity, strength, non-ferromagnetism, and high corrosion resistance. Flexinnium stent is developed with a highly flexible "S-link" which allows the stent to be more flexible hence more deliverable while it travels through vessels at the time of implant (Figure 1). Thickness of the strut is $60 \mu \mathrm{m}$. Flexinnium stent is available in lengths of $8,12,16,20,24,28,32,36,40,44$ and $48 \mathrm{~mm}$ and available diameters are 2.0, 2.25, 2.5, 2.75, 3.0, 3.5, 4.0 and $4.5 \mathrm{~mm}$. Flexinnium stent is majorly indicated for improving coronary luminal diameter in the following: patients with symptomatic ischemic heart disease (IHD) due to discrete de novo native coronary artery lesions; patients with symptomatic IHD due to lesions in saphenous vein bypass grafts; restoring coronary flow in patients experiencing acute myocardial infarction.

\subsection{Interventional Procedure and Adjunctive Medications}

All patients received a loading dose of $300 \mathrm{mg}$ of aspirin and clopidogrel (300 mg) or prasugrel $(60 \mathrm{mg}$ ) or ticagrelor (two tablets of $90 \mathrm{mg}$ each). The procedural anticoagulation was brought about with heparin. However, the intra-procedural administration of glycoprotein IIb/IIIa-inhibitor was at the investigator's preference. The procedure was performed according to the standard treatment guidelines of centre. All the patients received dual antiplatelet therapy (aspirin $75-300 \mathrm{mg}$ daily indefinitely and clopidogrel $75 \mathrm{mg}$ daily or prasugrel $10 \mathrm{mg}$ daily or ticagrelor $90 \mathrm{mg}$ twice daily for at least 12 months) after the procedure.

\subsection{Endpoints of the Study}

The endpoints of the study were as per Academic Research Consortium (ARC) consensus that suggested two composite endpoints, one that was device-oriented and another for overall patient-oriented clinical outcomes. The device-oriented composite includes cardiac death, myocardial infarction (MI) attributed to the target vessel, and target lesion revascularization (TLR). The broader patient-oriented composite outcomes include all-cause mortality, any MI, and any revascularization, includes target vessel revascularization (TVR) or revascularization of nontarget vessels. The occurrence of stent thrombosis (ST) was also analyzed according to ARC. Moreover, occurrence of in-stent restenosis (ISR) was also assessed.

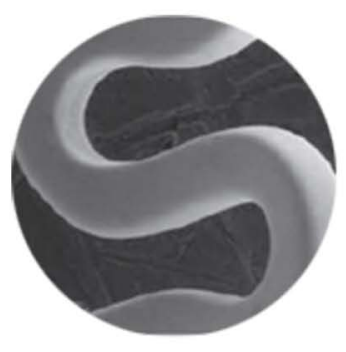

Unique Flexible 'S-Link'

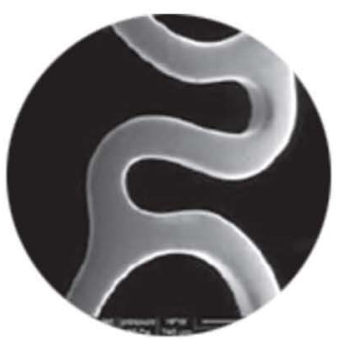

Excellent Electro-polished Stent Surface

Figure 1. Unique flexible S-link of Flexinnium stent. 


\subsection{Definitions of Endpoints and Clinical Events}

Deaths were classified as cardiac or non-cardiac death. Any death as a result of undetermined cause was reported as cardiac death. MI was diagnosed on the basis of the development of new Q-waves of more than 0.04 seconds in two or more contiguous leads, accompanied by a significant increase in the creatine kinase or MB isoform or troponin I or T levels; non-Q wave infarction was diagnosed as an increase in the creatine kinase level to more than three times the upper limit of the normal range with an accompanying elevation in the $\mathrm{MB}$ isoform or troponin $\mathrm{I}$ or $\mathrm{T}$ levels without development of new-Q-waves. A TLR was considered when there was restenosis or reocclusion within the stent or in adjacent $5 \mathrm{~mm}$ of distal or proximal segment. A TVR is defined as any repeat percutaneous intervention or surgical bypass of any segment of the target vessel. A ST was considered acute when it occurred within 24 hours, sub acute when it occurred between 1 and 30 days, and late when it occurred between 30 days and 1 year. A "Definite" ST was defined by symptoms suggestive of an acute coronary syndrome and angiographic or pathologic confirmation of stent thrombosis. A "Probable" ST was described as unexplained death within 30 days or target vessel myocardial infarction without angiographic confirmation of stent thrombosis. A "Possible" ST was defined as any unexplained death after 30 days [5].

\subsection{Follow-Up}

All patients underwent 12-month follow-up. Clinical follow-ups or telephonic conversation were scheduled at 12-month. Follow-up data were collected pertaining to current clinical status, prior hospitalisation and occurrence of any of the aforementioned adverse events. Further follow-up is scheduled to be taken at 24-month.

\subsection{Statistical Analysis}

Statistical analysis was performed with the use of Statistical Package for Social Sciences (SPSS; Chicago, IL, USA) program, version 15. The event-free survival curve was calculated according to the Kaplan-Meier method. Continuous variables are presented as mean \pm standard deviation (SD) and categorical variables as counts and percentages.

\section{Results}

\subsection{Baseline Demographics and Lesion Characteristics}

A total of 216 patients were enrolled in the study. The basic demographic details of the patients are outlined in Table 1 . The mean age was $54.4 \pm 9.8$ years; male gender represented 174 (80.6\%) patients; there were 76 (35.2\%) and 84 (38.9\%) patients of diabetes and hypertension, respectively. The most prevalent clinical presentation was anterior wall MI in 92 (42.6\%) patients, followed by inferior wall MI in 75 (34.7\%) patients. Left anterior descending artery involvement was found in 122 (50.8\%) lesions. Type B2 and $\mathrm{C}$ lesions accounted for $27(11.3 \%)$ and 122 (50.8\%) lesions, respectively. There were $81(33.8 \%)$ lesions with total occlusion. A total of 241 Flexinnium stents were implanted $(1.1 \pm 0.3$ stents per patient) with an average diameter and stent length of 2.7 
Table 1. Baseline demographic characteristics.

\begin{tabular}{cc}
\hline Characteristics & Flexinnium (216 patients) \\
\hline Age (mean \pm SD, yrs) & $54.4 \pm 9.8$ \\
Male, n (\%) & $174(80.6 \%)$ \\
Ciabetes mellitus, n (\%) & \\
Hypertension, n (\%) & $76(35.2 \%)$ \\
Tobacco chewer, n (\%) & $84(38.9 \%)$ \\
Smoker, n (\%) & $58(26.9 \%)$ \\
Previous stroke, n (\%) & $79(36.6 \%)$ \\
Previous MI, n (\%) & $8(3.7 \%)$ \\
Previous PCI, n (\%) & $15(6.9 \%)$ \\
Clinical presentation & $5(2.3 \%)$ \\
Anterior wall MI, n (\%) & $92(42.6 \%)$ \\
Inferior wall MI, n (\%) & $75(34.7 \%)$ \\
Non ST-elevation MI, n (\%) & $15(6.9 \%)$ \\
Stable angina, n (\%) & $15(6.9 \%)$ \\
Unstable angina, n (\%) & $19(8.8 \%)$ \\
\hline
\end{tabular}

MI-Myocardial Infarction; PCI-Percutaneous Coronary Intervention.

$\pm 0.2 \mathrm{~mm}$ and $21.6 \pm 8.0 \mathrm{~mm}$, respectively. The lesion and angiographic procedural details are summarized in Table 2 .

The factors that probably affect the outcomes subsequent to the implantation of Flexinnium in this study are diabetes, hypertension, smoking, presence of MI, and type of lesions. Diabetes and hypertension were prevalent in 35.2\% and 38.9\% patients, respectively. $36.6 \%$ patients were smokers. $77.3 \%$ patients presented with $\mathrm{MI}$ and $50.8 \%$ patients had type C lesions.

\subsection{Clinical Outcomes}

There were no in-hospital events in any of the patients. At 12-month follow-up, the device-oriented composite included cardiac death in $5(2.31 \%)$ patients, MI attributed to the target vessel in $3(1.39 \%)$ patients, and TLR in $8(3.70 \%)$ patients. The patientoriented composite constituted all-cause mortality in 6 patients, any MI in 3 patients, and any revascularization in 10 patients. There were two cases of TVR. The occurrence of ST was found in 7 patients. Of 7 patients with ST, one had acute ST, 6 had late ST; moreover, 3 had definite ST and 4 had probable ST. ISR occurred in 4 patients. The detailed clinical outcomes of the study are outlined in Table 3. Figure 2 illustrates cumulative incidences of cardiac death, MI and TLR at 12-month follow-up. One patient had stroke and one had gross gastrointestinal bleed requiring blood transfusion after 6 months. Long term follow-up of the study would further confirm safety and efficacy of the stent. 


\section{Discussion}

The present era has evolved with the sky-scraping use of PCI for treating coronary artery disease. DES has been commonly used in diverse conditions. The pervasive accep-

Table 2. Lesion and procedural characteristics.

\begin{tabular}{|c|c|}
\hline Characteristics & Patients $=216 /$ Lesions $=240$ \\
\hline \multicolumn{2}{|l|}{ Lesion location } \\
\hline Left anterior descending, $\mathrm{n}(\%)$ & $122(50.8 \%)$ \\
\hline Right coronary artery, $\mathrm{n}(\%)$ & $68(28.3 \%)$ \\
\hline Left circumflex, n (\%) & $50(20.8 \%)$ \\
\hline \multicolumn{2}{|l|}{ ACC/AHA lesion classification } \\
\hline $\mathrm{A}, \mathrm{n}(\%)$ & $34(14.2 \%)$ \\
\hline $\mathrm{B} 1, \mathrm{n}(\%)$ & $57(23.8 \%)$ \\
\hline $\mathrm{B} 2, \mathrm{n}(\%)$ & $27(11.3 \%)$ \\
\hline C, n (\%) & $122(50.8 \%)$ \\
\hline \multicolumn{2}{|l|}{ No. of diseased vessels } \\
\hline Single vessel disease, $\mathrm{n}(\%)$ & $168(77.8 \%)$ \\
\hline Double vessel disease, n (\%) & $48(22.2 \%)$ \\
\hline Total occlusion, $\mathrm{n}(\%)$ & $81(33.8 \%)$ \\
\hline Total no. of stent & $\mathrm{N}=241$ \\
\hline No. of stents per patient, (mean $\pm \mathrm{SD}, \mathrm{mm})$ & $1.1 \pm 0.3$ \\
\hline No. of stents per lesion, $($ mean $\pm S D, m m)$ & $1.0 \pm 0.1$ \\
\hline Average stent length, (mean $\pm S D, m m)$ & $21.6 \pm 8.0$ \\
\hline Average stent diameter, $($ mean $\pm \mathrm{SD}, \mathrm{mm})$ & $2.7 \pm 0.2$ \\
\hline
\end{tabular}

ACC/AHA-American College of Cardiology/American Heart Association.

Table 3. Cumulative clinical outcomes up to 12 -month $(\mathrm{n}=216)$.

\begin{tabular}{cc}
\hline \multicolumn{2}{c}{ Device-oriented composite outcomes } \\
Cardiac death, n (\%) & $5(2.31 \%)$ \\
MI (attributed to the target vessel), n (\%) & $3(1.39 \%)$ \\
Target lesion revascularization, $\mathrm{n}(\%)$ & $8(3.70 \%)$ \\
\hline Patient-oriented composite outcomes & $6(2.78 \%)$ \\
All-cause mortality, n (\%) & $3(1.39 \%)$ \\
Any MI (includes nontarget vessel territory), $\mathrm{n}(\%)$ & $10(4.62 \%)$ \\
\hline Any repeat revascularization (includes all target and nontarget vessel), $\mathrm{n}(\%)$ &
\end{tabular}



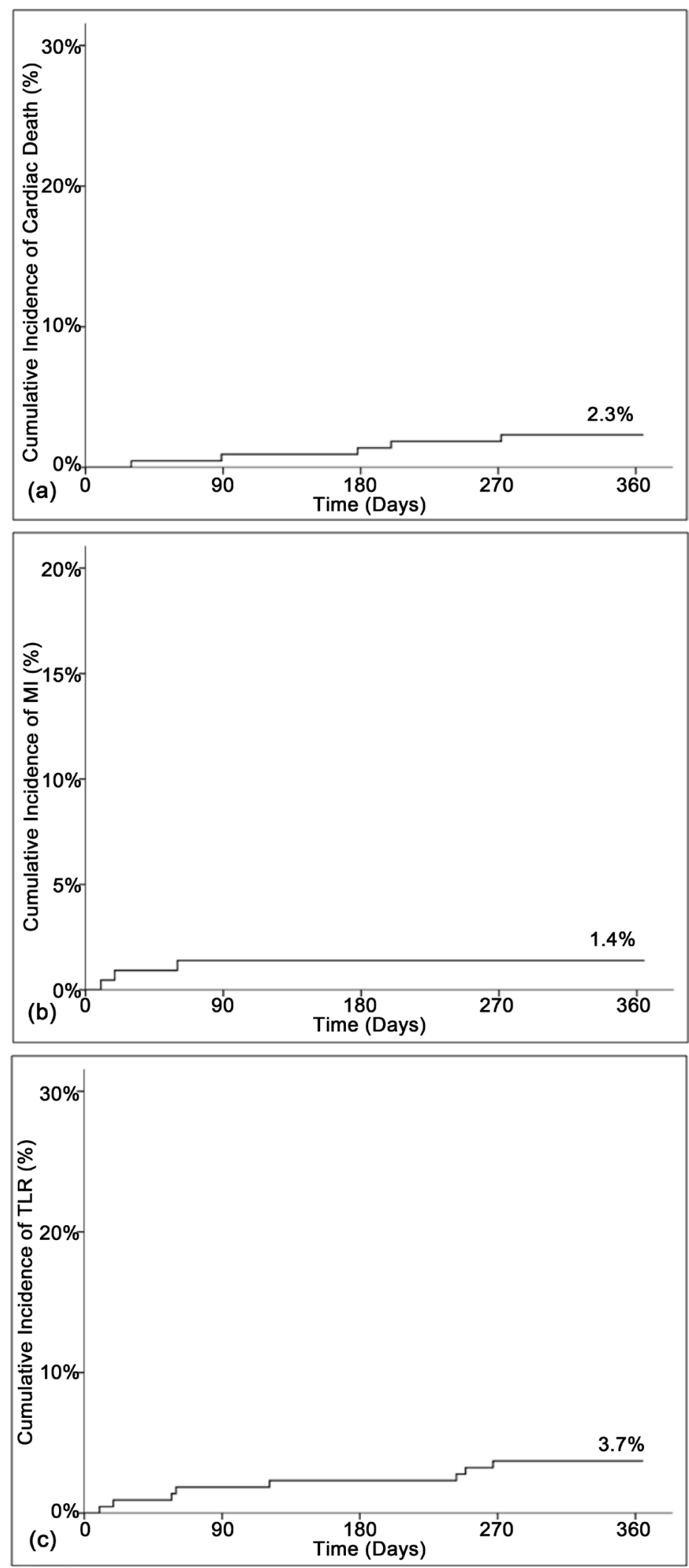

Figure 2. Cumulative incidences of (a) cardiac death, (b) MI and (c) TLR at 12-month follow-up. 
tance of DES and their corresponding low restenosis rates [6] might dwindle the clinical relevance of BMS. Nevertheless, BMS has worked its way up to be recognised in various indications like: large vessel diameter; ST-segment elevation myocardial infarction; advanced age; concomitant oral anticoagulant treatment; increased bleeding risk, cancer, or anemia; planned non-cardiac surgery within the next year; and anticipated poor DAPT compliance [7].

Moreover, various clinical scenarios favor BMS over DES. These are: patients in whom non elective surgery may be required; expected poor compliance with dual-antiplatelet therapy; intolerance/allergy to aspirin or clopidogrel/prasugrel/ticagrelor; bleeding risk; contraindication for long-term anticoagulation [8].

In the present study, patient population treated with Flexinnium stent, had higher rates of hypertension (38.9\%) and diabetes (35.2\%) and 36.6\% were smokers. Anterior and inferior wall MI was present in $42.6 \%$ and $34.7 \%$ patients, respectively. Left anterior descending artery involvement was found in 122 (50.8\%) lesions. It has been reported that presence of diabetes mellitus, complex lesions and left anterior descending artery along with other angiographic factors are predictive of development of 6-month in-stent restenosis [9], such that majority of LAD involvement adds to the possibility of increased risk in patients included in the present study. In present study type B2 and C lesions accounted for 27 (11.3\%) and 122 (50.8\%) lesions, respectively. Literature states that plaque burden and lesion length is directly related to complex lesion severity, as categorized according to American College of Cardiology/American Heart Association (ACC/AHA) classification. A long lesion, with considerable plaque burden, is a primary source of smooth muscle cells that then proliferate and form neointima [10] [11]. The combination of these factors makes the study population atypically complex. In spite of such complications, cumulative device-oriented composite at 12-month follow-up included $2.31 \%$ cardiac death, $1.39 \% \mathrm{MI}$ attributed to the target vessel, and $3.70 \%$ TLR.

Various factors have contributed for such low event rates in present study, these are: strut thickness and large vessels. It has been reported that strut thickness has been revealed to be an imperative determinant of the long-term restenosis rate [12]. Numerous comparative studies have established that stents with thinner struts appreciably reduce the incidence of restenosis by $\leq 40 \%$ relative to thicker strut devices [13]-[15]. In present study, the strut thickness was $60 \mu \mathrm{m}$, which contributed for lower rates of adverse events in patients. Moreover, there is an inverse relationship between vessel size and the incidence of adverse clinical outcomes after PCI with the use of BMS [16]. It has been reported that patients with small vessels have a higher incidence of restenosis following stent implantation than patients with large vessels [17]. In our study, large vessels were included with incorporation of stents of large diameter, which also led to lower incidence of events.

Previously, the CLASS study [12] reported 1.5\% death, 3.0\% MI and 9.4\% TLR at 6-month on using Medtronic Driver stent in patients with stable and unstable angina. Moreover, another study used Guidant Vision Multi-Link stent which reported rates of any MI, death, TLR, and TVR to be $0.8 \%, 1.2 \%, 4.3 \%$, and $0.8 \%$, respectively 6 -month 
follow-up [18]. In a study by Yamaji et al., at 14 months after BMS implantation, rate of MI, cardiac death, and TLR was found to be $0.5 \%, 3.2 \%$, and $16.1 \%$, respectively [19]. In ICAS registry, which included STEMI patients who underwent PCI in large coronary arteries, all cause death, MI, ST and TVR at a median follow-up of 12 months following BMS implantation were $4.35 \%, 0 \%, 1.57 \%$ and $18.9 \%$, respectively [20]. The results observed in the present study are comparable to those obtained in previous studies.

DESs have consistently abated restenosis rates compared to BMS and must be the treatment of choice for patients who are at high risk of restenosis. On the other hand, BMS remain a valuable alternative to DES in large vessels and in conditions of clinical contraindication to prolonged dual-antiplatelet therapy.

\section{Study Limitations}

The present study suffers a limitation that, the number of patients was low in comparison to other studies, so further studies on a larger number of patients are warranted.

\section{Conclusion}

The use of Flexinnium is associated with lower incidence of adverse events at 12-month follow-up. Thus, the FLEXUS study gives an idea about favorable safety and efficacy of the Flexinnium in unselected real-life patients with both simple and complex coronary lesions.

\section{References}

[1] Michon, P.B., Hathaway, M.F., Lindeen, K.C., Hanson, A.C., Schroeder, D.R., Oliver, W.C., et al. (2008) Time and Cardiac Risk of Surgery after Bare-Metal Stent Percutaneous Coronary Intervention. Anesthesiology, 109, 588-595. http://dx.doi.org/10.1097/ALN.0b013e318186ddf8

[2] Topol, E.J. and Serruys, P.W. (1998) Frontiers in Interventional Cardiology. Circulation, 98, 1802-1820. http://dx.doi.org/10.1161/01.CIR.98.17.1802

[3] Wenaweser, P., Rey, C., Eberli, F.R., Togni, M., Tüller, D., Locher, S., et al. (2005) Stent Thrombosis Following Bare-Metal Stent Implantation: Success of Emergency Percutaneous Coronary Intervention and Predictors of Adverse Outcome. European Heart Journal, 26, 1180-1187. http://dx.doi.org/10.1093/eurheartj/ehi135

[4] Habara, M., Terashima, M., Nasu, K., Kaneda, H., Inoue, K., Ito, T., et al. (2011) Difference of Tissue Characteristics between Early and Very Late Restenosis Lesions after Bare-Metal Stent Implantation: An Optical Coherence Tomography Study. Circulation: Cardiovascular Interventions, 4, 232-238. http://dx.doi.org/10.1161/CIRCINTERVENTIONS.110.959999

[5] Cutlip, D.E., Windecker, S., Mehran, R., Boam, A., Cohen, D.J., van Es, G.A., et al. (2007) Clinical End Points in Coronary Stent Trials: A Case for Standardized Definitions. Circulation, 115, 2344-2351. http://dx.doi.org/10.1161/CIRCULATIONAHA.106.685313

[6] Morice, M.-C., Serruys, P.W., Sousa, J.E., Fajadet, J., Ban Hayashi, E., Perin, M., et al. (2002) A Randomized Comparison of a Sirolimus-Eluting Stent with a Standard Stent for Coronary Revascularization. The New England Journal of Medicine, 346, 1773-1780. http://dx.doi.org/10.1056/NEJMoa012843

[7] Morice, M.-C., Urban, P., Greene, S., Schuler, G. and Chevalier, B. (2013) Why Are We Still Using Coronary Bare-Metal Stents? Journal of the American College of Cardiology, 61, 
1122-1123. http://dx.doi.org/10.1016/j.jacc.2012.11.049

[8] Ben-Dor, I., Waksman, R., Pichard, A.D., Lindsay, J. and Satler, L.F. (2011) The Current Role of Bare-Metal Stents. Cardiac Interventions Today, 40-45.

[9] Chen, Y.-L., Yip, H.-K., Chen, C.-J., Yang, C.-H., Fang, C.-Y., Hsieh, Y.-K., et al. (2009) Predictors of 6-Month Angiographic Restenosis inside Bare-Metal Stent in Chinese Patients with Coronary Artery Disease. Acta Cardiologica Sinica, 25, 1-6.

[10] Bai, H.-Z., Masuda, J., Sawa, Y., Nakano, S., Shirakura, R., Shimazaki, Y., et al. (1994) Neointima Formation after Vascular Stent Implantation. Spatial and Chronological Distribution of Smooth Muscle Cell Proliferation and Phenotypic Modulation. Arteriosclerosis, Thrombosis, and Vascular Biology, 14, 1846-1853. http://dx.doi.org/10.1161/01.ATV.14.11.1846

[11] Mehran, R., Dangas, G., Abizaid, A.S., Mintz, G.S., Lansky, A.J., Satler, L.F., et al. (1999) Angiographic Patterns of In-Stent Restenosis Classification and Implications for LongTerm Outcome. Circulation, 100, 1872-1878. http://dx.doi.org/10.1161/01.CIR.100.18.1872

[12] Legrand, V., Kelbaek, H., Hauptmann, K.E., Glogar, D., Rutsch, W., Grollier, G., et al. (2006) Clinical and Angiographic Analysis with a Cobalt Alloy Coronary Stent (Driver) in Stable and Unstable Angina Pectoris. American Journal of Cardiology, 97, 349-352. http://dx.doi.org/10.1016/j.amjcard.2005.08.051

[13] Briguori, C., Sarais, C., Pagnotta, P., Liistro, F., Montorfano, M., Chieffo, A., et al. (2002) In-Stent Restenosis in Small Coronary Arteries: Impact of Strut Thickness. Journal of the American College of Cardiology, 40, 403-409. http://dx.doi.org/10.1016/S0735-1097(02)01989-7

[14] Kastrati, A., Mehilli, J., Dirschinger, J., Dotzer, F., Schühlen, H., Neumann, F.-J., et al. (2001) Intracoronary Stenting and Angiographic Results Strut Thickness Effect on Restenosis Outcome (ISAR-STEREO) Trial. Circulation, 103, 2816-2821. http://dx.doi.org/10.1161/01.CIR.103.23.2816

[15] Ürgen Pache, J., Kastrati, A., Mehilli, J., Schühlen, H., Dotzer, F., Örg Hausleiter, J., et al. (2003) Intracoronary Stenting and Angiographic Results: Strut Thickness Effect on Restenosis Outcome (ISAR-STEREO-2) Trial. Journal of the American College of Cardiology, 41, 1283-1288. http://dx.doi.org/10.1016/S0735-1097(03)00119-0

[16] Cutlip, D.E., Chauhan, M.S., Baim, D.S., Ho, K.K., Popma, J.J., Carrozza, J.P., et al. (2002) Clinical Restenosis after Coronary Stenting: Perspectives from Multicenter Clinical Trials. Journal of the American College of Cardiology, 40, 2082-2089. http://dx.doi.org/10.1016/S0735-1097(02)02597-4

[17] Elezi, S., Kastrati, A., Neumann, F.-J., Hadamitzky, M., Dirschinger, J. and Schömig, A. (1998) Vessel Size and Long-Term Outcome after Coronary Stent Placement. Circulation, 98, 1875-1880. http://dx.doi.org/10.1161/01.CIR.98.18.1875

[18] Kereiakes, D.J., Cox, D.A., Hermiller, J.B., Midei, M.G., Bachinsky, W.B., Nukta, E.D., et al. (2003) Usefulness of a Cobalt Chromium Coronary Stent Alloy. American Journal of Cardiology, 92, 463-466. http://dx.doi.org/10.1016/S0002-9149(03)00669-6

[19] Yamaji, K., Kimura, T., Morimoto, T., Nakagawa, Y., Inoue, K., Soga, Y., et al. (2010) Very Long-Term (15 to 20 Years) Clinical and Angiographic Outcome after Coronary Bare Metal Stent Implantation. Circulation: Cardiovascular Interventions, 3, 468-475. http://dx.doi.org/10.1161/CIRCINTERVENTIONS.110.958249

[20] Abe, D., Sato, A., Maruta, S., Misaki, M., Hoshi, T., Takeyasu, N., et al. (2013) Clinical Value of Drug-Eluting Stent over Bare-Metal Stents in Large Coronary Arteries in the Patients with ST-Segment Elevation Myocardial Infarction. European Heart Journal, 34, 3034. http://dx.doi.org/10.1161/CIRCINTERVENTIONS.110.958249 
Submit or recommend next manuscript to SCIRP and we will provide best service for you:

Accepting pre-submission inquiries through Email, Facebook, LinkedIn, Twitter, etc.

A wide selection of journals (inclusive of 9 subjects, more than 200 journals)

Providing 24-hour high-quality service

User-friendly online submission system

Fair and swift peer-review system

Efficient typesetting and proofreading procedure

Display of the result of downloads and visits, as well as the number of cited articles

Maximum dissemination of your research work

Submit your manuscript at: http://papersubmission.scirp.org/

Or contactwjcd@scirp.org 